\title{
The Pedagogical Potentials of Integrating Augmented Reality: Revisiting Gagné ISD Framework
}

\author{
Mohamed Abdelmagid \\ International Islamic University Malaysia, \\ Faculty of Education, \\ Department of Curriculum and Instruction
}

\begin{abstract}
The concept of Augmented Reality (AR) technology has paved a new innovation in modern teaching methods as a creative tool for blended learning. Although there has been a robust literatures on augmented reality, educators and other stakeholders are unaware of the AR benefits even reluctant to take up concrete steps towards integrating AR into teaching and learning settings. This attitude requires more efforts by researchers to shed light on the affordances and capabilities of AR in educating the new generation students in today's schools. Therefore, this paper attempts to highlight the pedagogical potentials of AR technology in conjunction with Gagné ISD Model (1998). Thus, the guidelines of instructional practices and the quality of student learning are revisited. This paper will contribute to the theoretical aspect of integrating AR in teaching and learning effectively and efficiently. Further, a proposed model for teachers to employ various pedagogical strategies while using the instructional model of Gagné's Nine Events in AR-supported learning process will be presented. The present paper will adopt the analytical approach based on meta analysis by reviewing journal articles on using AR in education from a variety of sources such as Web of Science, ESCI indexes, and SCI-EXPANDED. For this review, a number of 28 articles, conducted between 2013 and 2018, on the use of $A R$ in educational context were examined and reviewed.
\end{abstract}

Keywords: Augmented Reality, Digital Natives, Gagné ISD Model, Educational Technologies, Teaching and learning, Technology-enhanced learning

\section{INTRODUCTION}

Educational systems have been constantly exposed to scientific attempts to review, adjust, and improve the instructional performance to meet the increasing learning needs of students. Various research studies were conducted to provide multiple theories and models to help teachers adopt the most efficient instructional strategies to accomplish the planned objectives. One of the key research contributions is Gagné's Instructional Systems Design (ISD) (1998), which comprises a nine-step model and caters to support the information and mental processing while learning through proposing a practical sequence of certain instructional events to achieve the desired learning outcomes. This model is considered as a solid method to provide a systematic and efficient instructional flow that marks the behaviorist approach to learning and drives teachers by structured, holistic view to the instructional practices (Khadjooi, Rostami, \& Ishaq, 2011). The integrity and usefulness of Gagné's model in guiding the teaching practices could be even higher when connected to diverse pedagogical strategies and viewed in the light of the huge advancement of modern technology.

The evolution of technology occurs consistently and rapidly in a way that no one has ever imagined. Technology has become available everywhere, entwined in almost every part of our daily routines. It has a great impact on how we live, communicate, work and most prominently 
learn. This increasing phenomenal change has brought a considerable impact on education in the form of numerous changes in the teaching process that involves the increased demand of integrating new technological resources in education to support teachers' work and accommodate students' learning styles. It is important to remember that upgrading the educational environment can open new horizons of creativity for teachers and students. It is also essential for reaching effective, sustainable development in education in order to understand, plan and manage current and future life issues.

Amid an influx of technological tools, Augmented Reality (AR) has been one of the most interesting and pervasive technologies nowadays especially with the big surge in using modern mobile gadgets. AR is a cutting-edge concept of technology that helps enhance and augment how users view the reality. During the past few years, AR has become a prominent trend amongst other innovative technologies in several settings such as business marketing, maintenance, tourism, gaming, training, and more recently in education (Laine, 2018; MartínGutiérrez, Mora, Añorbe-Díaz, \& González-Marrero, 2017). Therefore, the idea of utilising AR within specific supporting pedagogical strategies in conjunction with the nine-events model of Gagné is expected to provide teachers with unique, effective instructional experiences.

\section{Augmented Reality: Concepts, Mechanism and Prospects}

Augmented Reality can be described as a technology system that allows both real and virtual objects to co-exist simultaneously and provides interactivity in real-time (Azuma, 1997). According to Gopalan, Zulkifli, and Bakar (2016), AR is a platform that produces a fusion of real world and virtual world environment scenes that augments the real setting with additional data, for instance, images, audio, video, text or/and animation, forming an integrated, innovative perception. In other words, AR combines the three dimensions (3D) of computergenerated objects (images, videos, animations) to be superimposed on the real scene. The term Augmented Reality was coined by Prof. Thomas Caudell, a Boeing Aerospace scientist, around 1992; when it was used for pilot training programmes. Since then, AR has been an existing theory for various domains like training, advertising, tourism, medicine and many others.

AR system works in three successive stages: recognition, tracking, and mix (Sdk, Amin, and Govilkar, 2015). The recognition or acquisition stage begins when the AR-enabled tracker (an image linked to the augmented reality element) gets recognised through the device camera which can be a Head Mounted Display (HMD) or the built-in cameras in laptops, tablets or smartphones. Then, the AR-enabled tracker triggers the already designed and installed AR software to render virtual components. Finally, the mixing stage occurs when multiple media contents, such as 3D object, text, animation, video, and/or audio segment, are superimposed over the real-life scene with which the user can interact (Figure 1). As mentioned earlier, a wide range of electronic gadgets can be used for producing AR including smartphones, iPads, laptops, and desktop computers with webcams to enhance the content in greater details or just get an idea of what it looks like in real space. Currently, what is called "handheld devices" or smartphones have built-in cameras, motion sensors and big screens with high resolution for delivering highly-sophisticated, innovative AR learning experiences. 


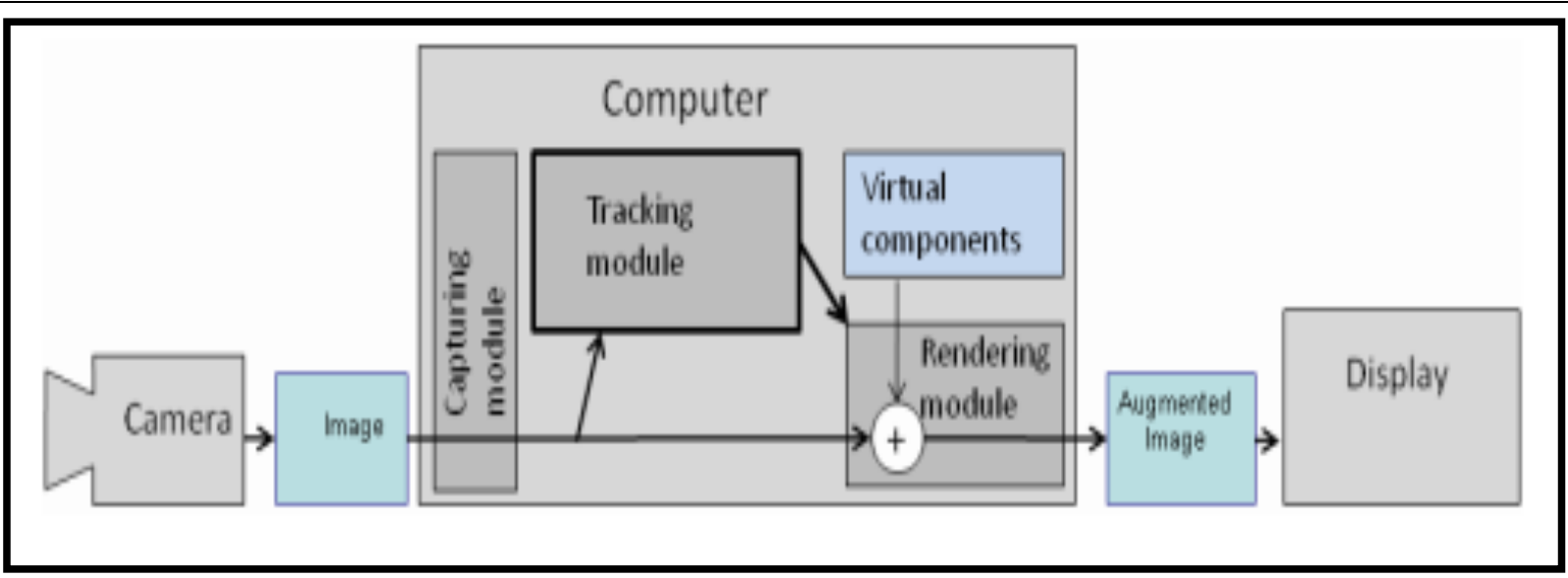

Fig. 1 Illustration of AR Mechanism by Siltanen (2012)

With regard to its innovation, AR has added further dimensions to the way people interact with the world. Per Roman (2018) posits that AR has revolutionised the way people interact with the world through eliminating the barrier between the physical and the digital. The ARdesigned applications seamlessly merge both the physical and the digital which significantly allows to augmenting the perceptions of users and predicts a big rise in the adoption of augmented reality in various areas of life (Bullhound, 2018). Recent business indicators reveal the surge in funding and employing AR in various life sectors. International Data Corporation (IDC) stated that AR is viewed as one of the fast growing Essential Eight technologies amongst more than 150 emerging technologies in 2017; with estimation of worldwide market to grow from $\$ 5.2$ billion in 2016 up to more than $\$ 160$ billion by 2020 (Pace, Manuri, \& Sanna, 2018) (Fig. 2). Additionally, it is expected that around 2 billion users will be using AR-designed apps through their Smartphone by 2021. Thus, a lot of digital enterprises have been developing thousands of AR apps in diverse fields such as entertainment, medical surgery, training courses, technical guidance, marketing to impress the rapidly increasing AR-app users. At present, this extensive proliferation of AR is likely to reach unprecedented level in 2018 with more progress and creative applications (Deloitte, 2018). Experts argue that the area of education is expected to get as little as $26 \%$ of the total AR investment in 2018 which ranked third after Gaming and Medical Services (Coie, 2018). Although this progress in using AR may seem quite impressive compared to the popularity of other major sectors, yet, the educational system is likely to exploit the affordance of AR more thoroughly within the coming few years.

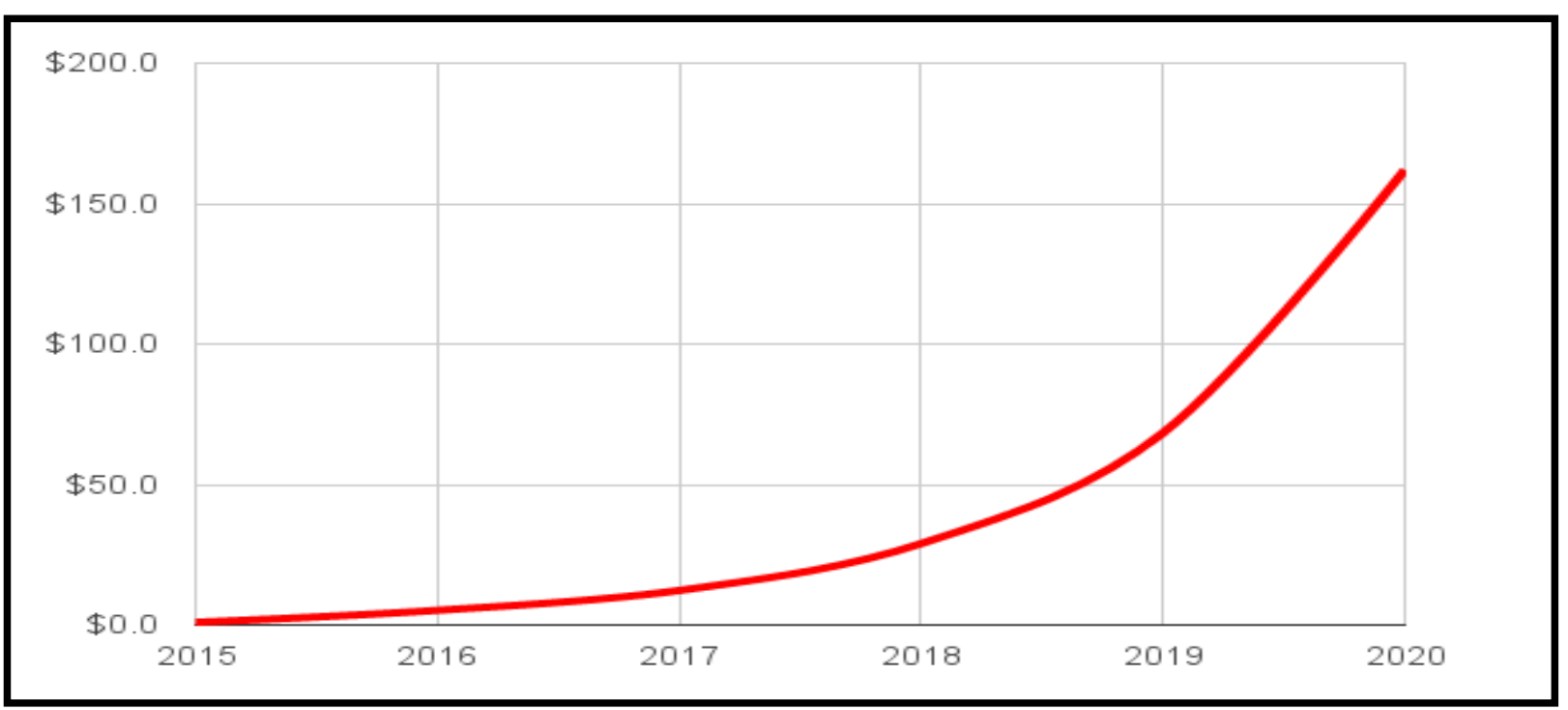

Fig. 2 Global AR Market Forecast, in Billions. (IDC, 2018) 
Consequently, the recent figures affirm that AR has already started to grab the attention and awareness of professionals in most life domains who could realise its positive influence in making a real difference in society currently and the years to come which attracts more users to get involved so fast. The fastest and most frequent AR users could be the young generation receiving education in today's schools who are figuratively called the "Generation Z" or the "Digital Natives".

\section{Augmented Reality in Education}

The term "education" primarily denotes the act of a purposeful, designed intervention aiming at making a behavioural change in individual attitude. In education, the utmost target is to accomplish learning that enables learners to explain, apply, list and demonstrate their perceived knowledge and skills in a way that reflects a change in attitude (Monroe, 2013). Educators consistently seek novel methods to maximise the learning outcomes and support positive change of students' behaviour, as well as to accommodate the changing learning needs of modern generation.

The constant improvement in the education system is getting faster day by day since it is an integral part of the rapidly evolving life. With the advent of innovative technologies during the past years, education has been integrating several technological types such as the PowerPoint presentations, classroom projectors, smart boards, and many others. This consistent adoption of modern technology aims to elevate the students' interest in a process of quality learning. Upon the craze of AR-based Pokémon GO in the summer of 2016, educationists started to conceive the potential affordances of AR for education. Since then, the concept of using AR in the educational domain has immensely received increasing interest and research work in order to investigate its influence on teaching and learning.

The literature reviews on the incorporation of AR in education has witnessed considerable progress during the past few years. A wide range of studies have been conducted on integrating AR into the learning of diverse curricular areas, such as science (Gopalan et al., 2016; Kamarainen et al., 2013), language learning (Gopalan et al., 2016; Moralishvili \& Akaki, 2014; Solak \& Cakir, 2015), architecture (Megahed, 2014), ICT (Sampaio \& Almeida, 2016), chemistry (Prokopenko, 2017), mathematics and geometry (Bujak et al, 2013; Sommerauer \& Müller, 2014), and geography (Chen \& Wang, 2015; Hsiao et al., 2016). Various research studies have also been conducted at different educational levels: early childhood education (Cascales, Pérez-López, \& Contero, 2013; Safar, 2017; Yilmaz, 2016), primary schools (Alkhattabi, 2017), secondary schools ( Bressler \& Bodzin, 2013; Gopalan et al., 2016), and university level and higher education (Rodríguez, 2013). This diverse literature reveals the recent increasing interest by various researchers to examine the effectiveness and potential affordances of AR in leveraging the teaching and learning quality in meaningful, successful educational contexts.

\section{Pedagogical Potentials of Augmented Reality}

The theme of pedagogical uses of AR has become one of the key topics amid the current significant body of studies on educational technology (Fotaris et al., 2017; FitzGerald et al., 2013). It might be assumed that the most promising technology amongst all emerging digital technologies that have the potential for leveraging the integral quality of education is augmented reality. Since the onset of its incorporation in education, AR has become a key contributor in revolutionizing the traditional pedagogical strategies in a way that led educationists to constantly investigate AR in diverse learning contexts (Bitter \& Corral, 2014; Laine, 2018; Saltan \& Arslan, 2017; Sampaio \& Almeida, 2016; Shirazi \& Behzadan, 2013; Silva, Roberto, \& Teichrieb, 2015; Wu, Lee, Chang, \& Liang, 2013). Most significantly, the multiple AR 
pedagogical components are essential in providing the structure through which educational settings can be drastically improved. The review of AR literature in educational contexts has revealed the diverse pedagogical potentials as follows:

\section{Increased Attention}

From a pedagogical perspective, integrating AR into the learning activities can maximise the level and time span of students' attention by adding up computer-generated virtual elements to the real environment. This process of augmenting the learning context together with the collaborative, multi-user learning environment allows for vivid interactions and boosted communications among students. Using a combination of multimedia and animation elements appeal students' minds more than merely use of text and images in traditional study books (Diegmann, Schmidt-kraepelin, Eynden, \& Basten, 2015; Safar, 2017; Shirazi \& Behzadan, 2013). Since the biggest motive of teachers is to capture the attention of learners throughout the learning session in appealing and engaging context, students often describe their AR-based learning as highly interesting and interactive. This may indicate higher attention when students become involved in interactive, interesting learning context; and then spontaneously develop higher levels of interpersonal communication and become willing to proceed to learn for longer time.

\section{Increased Perception}

Abundance of literatures show that one of the major pedagogical potentials of AR is the ability to exploit virtual objects in establishing higher level of perception that provides students with better understanding through manipulation the properties and relationships of objects in reallife context (Bower et al., 2014; Diaz, Hincapié, \& Moreno, 2015; Slijepcevic, 2013). Although such key function can be achieved by other technologies, AR excels in constituting clear representations of spatial concepts and providing a contextualised connection between virtual components and real-life scene. Additionally, AR permits learners to obtain increased level of cognitive perception in a cognitive overload risk-free learning setting which avoids students from getting exposed to excessive information or low spatial abilities (Cheng, 2017; Safar, 2017; Slijepcevic, 2013). The idea of mixing both pictorial and tactile spatial knowledge offered by AR results in higher levels of interaction, manipulation and more rapid, accurate perception. Furthermore, as for teachers, at the onset of applying AR in instructional settings, teachers had some challenges with AR due to an overwhelming feeling of the new technology and who do utilise it adequately (Devaney, 2010; Dunleavy et al., 2009). However, recent studies revealed an increased level of teachers' perception of integrating AR with more efficiency which can be viewed as a result of the excessive use of new technologies and perceived effectiveness and ease of use of AR.

\section{Authentic and Contextualized Learning}

Based on the key feature of AR in adding real-world components into the classroom, the idea of creating authentic and contextualised learning experiences is no longer difficult. The concept of AR aligns with the Situated Learning Theory (SLT) that indicates effective learning is possible to occur within a specific context based on the learners' level of interactivity (Brown, Collins, \& Duguid, 1989). By integrating AR, learners are capable to get engaged in a sequence of authentic activities and experiences that simulate the real-world tasks. As a consequence, by combing real and virtual components in engaging learning settings, AR can be employed in a situated learning to bridge the gap between practical and theoretical learning practices (Cabero \& Barroso, 2016; Dunleavy \& Dede, 2014; Pace et al., 2018). Thus, through the AR simulation of real-world context, students can seamlessly apply and transfer their learning experiences into varied future situations. 


\section{Learning Through Discovery and Problem-Solving}

One of the main effective pedagogical approaches is to get learners involved in active and experiential contexts where they are able to discover and solve problems. During vivid learning settings, learners are inspired to construct their thinking, understanding and knowledge through deeper level of reflection and engagement (Champney et al., 2015). This approach is substantiated by the constructivist learning theory through creating an environment where learning occurs by means of discovery and solving problems (Manganello, 2010). Using the AR-based information overlays significantly helps learners to develop a deeper cognitive level when engaged in the learning tasks and concepts as well as allows them to make strong connections with their prior knowledge. Students' problem-solving and discovery experiences are boosted when involved in AR-assisted learning settings through providing students with information about the real-life settings along with considering certain objects to be recognised or studied (Bethany Cohn Sansone, 2015; Bower et al., 2014; Cabero \& Barroso, 2016; Diegmann et al., 2015). Having the opportunity to undergo authentic inquiries and problem-solving trials in AR-supported learning contexts is a promising approach where students are likely to create various conceptual modes consistent with their previous knowledge and the new learning experience.

\section{Enquiry-Based Learning}

The strategy of enquiry-based learning indicates seeking conclusions through raising a set of questions and assumptions that get to be investigated against certain facts or proofs in a sequential, systematic process. Together with using technology, this learning approach is highly functional in developing learners' higher thinking skills (Edelson et al., 1999). AR is capable to support the enquiry-based learning through providing new updated forms of enquiry as well as allowing students to get information contextually adequate to the investigated target topic (Bower et al., 2014; Rezende, Albuquerque, \& Ambrosio, 2017; Saltan \& Arslan, 2017). This unique potential allows educators to create multiple collaborative pedagogical methods through various practices such as jigsaw and differentiated role-play which support the inquiry-based learning activities. As a consequence, AR enables learners to manipulate multiple virtual models contextually in a real-world scene that leads to easy, unlimited access to information relevant to the enquiry being conducted.

\section{Games-Based Learning}

Studies show that gamification and game-based learning are so effective in promoting students' engagement and adding more fun to the learning setting (Prokopenko, 2017). According to Prensky (2001) when games are incorporated into the learning process and become functioned in the educational objectives, learners significantly develop more attention, enjoyment, and interest in learning. With augmented reality applications, the immersive games-based learning is empowered and facilitated by making a digital narrative for learners to role play, as well as allowing them to access authentic resources and contextualized information and experiences (Fotaris, Pellas, Kazanidis, \& Macedonia, 2017; Hung et al., 2017; Pellas, Fotaris, Kazanidis, Macedonia, \& Wells, 2018; Sliusar, 2017). Based on the outstanding feature of AR of adding a real-life visualisation by adding animation and other multimedia effects to the learning context, learners' skills and perceptions can be increasingly emphasised seamlessly and rapidly when using the game-based learning approach. That may conclude the advantages of AR game-based learning as increasing motivation, enhancing collaboration, boosting knowledge retention, and maximizing learning fun and enjoyment.

\section{Individualising Instruction}

Teachers need to keep changing and improving their teaching styles in order to accommodate learners' diverse learning needs. One of the effective teaching methods is individualised 
instruction (Pretti-Frontczak \& Bricker, 2004) which includes four main aspects: 1. identifying the personal interests and abilities of learners, 2. providing tailored learning opportunities to improve learners' abilities, 3. adding several interactive tasks to support students' learning. and 4. monitoring their progress to ensure achieving the intended goals. This method of teaching is so significant when targeting low achievers in different subject matters or when students feel bored or/and frustrated to proceed to learn (Brophy, 2010). When integrating AR into the classroom practices, teachers are able to transfer the classroom environment from teacher-centered to more engaging learner-centered setting due to the unique characteristics of AR in supporting students' independent learning. It also helps teachers to act as facilitators and permits an effective individualized instruction in a typical group setting based on the individual capabilities among students (Cabero \& Barroso, 2016; Diegmann et al., 2015). AR lends itself well to assist teachers to adapt their teaching to the multiple learning styles and intelligence types among students.

\section{Learning styles among the digital natives: Gagne framework revisited}

Many scholars such as Oblinger and Oblinger (2005), Palfrey and Gasser (2008) and Prensky (2001a) and others have described the new generation as different than the previous ones due to their immersion in a world infused with various highly-sophisticated technologies which make them behave unlike previous generations. It is argued that the new generation members think differently, communicate differently, interact differently and most importantly learn differently. According to Dede (2005a, 2005b), technology extensive diffusion in all areas of life has reshaped the mindset of contemporary learners and shifted their learning styles. This might lead to reconsider how new generation should be perceived in relation to their personal characteristics and learning styles and needs.

The generation born after 1998 and learn in today's schools are called "Generation Z". The age of this young generation currently spans from pre-schoolers to teenagers. According to Sladek and Grabinger (2016), individuals of Generation Z are referred to as "Technoholics," due to their sophistication and immersion in the world of technology. Due to the extreme technology integration into their lives from the early age, they are also described as "digital integrators". Most significantly, Prensky (2001) coined the term "Digital Natives" to depict the extreme connection between individuals of this generation and digital life from the early age since technology dominates almost all areas of their relationships and lifestyle. This superior generation is visually engaged and educationally transformed. It is the generation featured with experimenting Google Glass, nano-computing, 3-D printing and driverless cars. Digital Natives are incredibly connected to their gadgets which may express some features of their personality; it is a part of who they are.

In education, they are technology savvy and intelligent that shapes their learning style to learn differently. Such huge ability to use technology has empowered and expanded their minds and accommodated their behaviour towards changes in the society. They are image-driven who start to perceive graphics before literacy skills and think fast in non-linear style. Digital natives are time-bound with strong sense of immediacy and success-oriented who opt to get instant reward and gratification. They are global-minded who use the varied tools of social media to communicate and be updated about life. Although they believe change can easily occur overnight and rapidly get bored, they prefer to handle multitasks learning, obtain information quickly, and learn communicatively and interactively rather than by lecturing (Jones \& Shao, 2011; Sladek \& Grabinger, 2016). All these characteristics affirm the highly sophisticated, technology-bound mindset of $\mathrm{Z}$ generation that necessitates addressing the learning needs of contemporary learners as intelligently and competently as they deserve (Sladek \& Grabinger, 2016). Digital Native learners tend to view technology as the major tool of their learning 
process because they believe it makes their learning more enjoyable and motivating which can be efficiently fulfilled by integrating up-to-date technologies, such as AR, guided by a particular model for leveraging the teaching/learning process altogether.

\section{Gagné's ISD Framework}

Gagné-Briggs (1992) presented the instructional systems design (ISD) model that consists of a series of nine-events. ISD model provides a systematic sequence of teachers' instruction which is regarded by many educationalists as the most established and effective among all ISD models (Tsai, 2008). It is viewed as a behaviourist model that supports the information and mental processing through proposing a practical sequence of certain instructional events to achieve the desired learning outcomes. The model also caters to different learning styles and allows to ease the process of learning (Wong, 2018). Besides, Gagné confirms that instruction is better conceived as a sequence of external factors purposely formulated to boost the internal process of learning. Each instructional event in the model is meant to back up particular learning outcomes.

The nine-step paradigm sets up a comprehensive instructional sequence, similar to heuristic guidelines, ranging from gaining attention to enhancing retention and transfer that leads to durable learning. The systematic sequence allows teachers to highly monitor students' learning in each step before moving on to the next that makes it a process-oriented model without missing any major parts of the learning process. However, teachers are not consistently required to apply the events of instruction in their typical sequence but teachers may use them interchangeably based on the learning setting, type of knowledge content, learners' capabilities and learning styles and any further variables (Ngussa \& Centre, 2014). The nine-events paradigm of Gagné's ISD model consists of the following:

1. Gaining learners' attention

2. Informing the learner of the objective

3. Stimulating recall of prior learning

4. Presenting the knowledge content

5. Providing learning guidance

6. Eliciting the performance

7. Providing feedback

8. Assessing the performance

9. Enhancing retention and transfer

Although applying the nine-events model fairly yields a holistic view to the teaching and helps teachers to pursue systematic instructional practices by the guidelines presented in the form of staggered lesson plans which is likely to achieve the learning objectives, it seems to lack a specific, essential step for planning which negatively affects teachers' ability to relate their instruction to solid pedagogical background. Such critical pitfall can be settled by adding an initial stage of planning to ensure accurate mental and physical design prior to starting the main process of instruction.

\section{Proposed Instruction Model for AR Integration}

Upon reviewing the characteristics of new generation students and the advantages of integrating AR-supported learning in modern classroom instruction, a new instruction model can be proposed through using Gagné's nine events in conjunction with the pedagogical potentials of AR technology. This model would present a paradigm combining teachercentered practices with convenient pedagogical strategies for upgrading and guiding the whole instructional practices and enhancing the quality of students' learning as well. Table 1 presents a proposed matrix for teachers to employ various pedagogical strategies while using the 
instructional model of Gagné's Nine Events in AR-supported learning process. Besides, teachers can adapt, interchange, or pass over each of the proposed strategies based on their teaching styles and students' interest and needs.

Table. 1 Proposed Matrix of Integrating AR-supported Pedagogical Strategies into Gagné NineEvent Model

\begin{tabular}{|c|c|c|}
\hline Presentation & Gagné: Nine Events & AR-Supported Pedagogical Strategies \\
\hline Planning & $\begin{array}{l}\text { 1. prepare for the lesson } \\
\text { (objectives, learning activities and } \\
\text { materials, teaching strategies and } \\
\text { tools) }\end{array}$ & \\
\hline \multirow[t]{3}{*}{ Introduction } & 2. Gain attention of learners & \multirow[t]{2}{*}{ Increased attention } \\
\hline & 3. Inform learners of objectives & \\
\hline & 4. Stimulate recall of prior learning & Games-based learning \\
\hline \multirow[t]{2}{*}{ Content } & 5. Present the content & \multirow{2}{*}{$\begin{array}{l}\text { Authentic and contextualised learning } \\
\text { Enquiry-based learning }\end{array}$} \\
\hline & 6. Provide learning guidance & \\
\hline \multirow[t]{3}{*}{ Assessment } & 7. Elicit performance (practice) & $\begin{array}{l}\text { Individualising instruction } \\
\text { Learning through discovery and } \\
\text { problem-solving }\end{array}$ \\
\hline & 8. Provide feedback to learners & \multirow{2}{*}{ Increased Perception } \\
\hline & 9. Assess performance & \\
\hline Summary & 10. Enhance retention and transfer & \\
\hline
\end{tabular}

The model comprises five main phases (planning, introduction, content, assessment, summary). For planning, teachers prepare a draft of the lesson objectives to be achieved by the students' learning. It also includes relevant learning activities and teaching strategies as well as all materials and tools necessary to implement the lesson. Since AR is adopted, some AR apps can be utilised by teachers to prepare the different learning activities throughout the lesson. For example, Layer, Aurasma and Google's ARCore are free and easy-to-use platforms that helps teachers who have minimal experience with technology to build varied AR-designed educational activities. These two apps and many others helps teachers to produce certain AR experiences simply for any learning task in the lesson plan.

In the next phase, teachers can start the introduction phase by capturing students' attention and interest through using some AR funny animation and allowing students to interact with and enjoy them. Then, teachers come to inform learners of the lesson objectives that initiate the internal process of expectancy and make students aware of what final performance is expected. Teachers can simply give the following direct statement at this point of the session: "upon completing this lesson you will be able to". After that, teachers are to manage to recall of students' prior learning related to the lesson to be given by using any game-building programme or application, such as Google's ARCore that creates simple AR-based games on the previously taught knowledge content. Having students recall their prior knowledge and personal experiences related to the session's theme is likely to establish strong connections between the previous and current learning process.

The content phase is firstly marked with presenting the target knowledge content or skills. Teachers need to select and organise the content meaningfully according to the lesson objectives to be demonstrated using a variety of media. In this stage, AR significantly allows for authentic and contextualised learning by making learners capable to get engaged in a sequence 
of authentic activities and experiences that simulate the real-world tasks and bridge the gap between practical and theoretical learning practices which helps students to perceive and retain better. Teachers can uses any AR building application to develop simple, creative AR presentation of the target content. As a second step in this phase, teachers move to providing learning guidance to know what appropriate actions make quality learning to help learners encode information and keep it for long. This event can benefit from the enquiry-based learning of AR through providing new updated forms of enquiry by having a jigsaw or differentiated role-play which support learners in making clear connection between what they know and what is being learned.

Upon doing the content phase, the action now turns to students. The assessment phase is planned to be have three successive events. Firstly, teachers can elicit the students' performance through allowing them practise the new skill or drilling on the presented information. Due to the key potentials of AR in individualising instruction and learning through discovery and problem-solving, teachers can plan and design certain AR-based experiences that provide each student an opportunity to assert their understanding and trigger students' curiosity to discover that could increase the likelihood of mastering the learned content. Then, while observing students doing the practice tasks, teachers can provide individual and immediate feedback to guide students' performance and offer answers to their inquiries. This stage of feedback allows teachers to review their instruction and apply immediate adjustment when necessary in order to enhance the effectiveness of instruction. Due to the importance of evaluation in the teaching-learning process, teachers at this point can manage to assess students' interactions during the classroom. Screening students in the formative assessment helps teachers reach students who need special assistance, determine students' points of weakness, and identify their instructional needs. Both stages of providing feedback to and assessing students' performance significantly increase students' perception of the target knowledge content and skills.

At the final phase, summary takes place as a wrap up stage in which teachers manage to ensure that instruction has enhanced retention and transfer by providing students with practices and drilling information. Such repetition of learned concepts facilitates reaching retention enhancement even though students dislike it. The optimal target of instruction is achieving transfer of knowledge and skills to learners who consequently become able to apply it to new problems and situations.

\section{CONCLUSION}

Reviewing the pedagogical potentials of augmented reality is not only important for affirming the effectiveness of AR in enhancing the standards and outcomes of learning, but also guiding educators to diverse approaches AR can be utilised and manipulated for uplifting their instructional experiences. Although more teachers may have used AR-based applications in different school settings, yet the majority of these practices simply integrate AR into the curricular activities rather than having it grounded on specific learning theory or pedagogical framework which may undermine the effectiveness of instruction and even render negative learning experiences (Laine, 2018). This inadequacy of application might be caused by the recentness of AR utilisation in educational context and lacking of teachers' training and updating their professional practices (Saltan \& Arslan, 2017).

Additionally, if it is believed that technology nowadays poses a big challenge to educators in terms of making the best use of pedagogical practices (Filer, 2010), it is highly recommended for teachers to perceive how to integrate AR with pedagogical approaches in a systematic, planned framework, such as Gagné nine-event model, in order to couple both technology-based 
pedagogical instruction and traditional instructional methods for elevating the quality of learning. There is also a dire need to consider curricular redesign based on the latest research findings and technological innovations together with supporting teachers' professional development to support an emerging pedagogical shift since the greatest success is attainable when teachers receive adequate training and guidance in terms of exploiting technology tools to support pedagogical strategies.

The proposed model of instruction collaborates AR pedagogical strategies with Gagné nineevent model to offer a sample of how teachers can exploit the state-of-art technology of AR in a systematic and effective method. Teachers may adapt, interchange, or pass over any part in the proposed model based on the learning styles and abilities of students as well as the nature of content to be delivered. It is believed that further modifications may be applied to the model, though it is considered an attempt to present certain guidelines to teachers who may find it too hard to design an AR-supported lesson plan creatively and proficiently. For achieving this target, teachers need to get introduced to some basic applications for AR building which needs few training sessions and some expert guidance together with equipping the classrooms with basic technology tools for applying AR. School administrations are highly required to accommodate these significant requirements for supporting teachers' sustainable development, students' learning quality, and the whole learning outcomes.

All in all, the numerous pedagogical potentials of AR could provide educators with a broad vision to address the real world problems through the abstract learning theories. By utilising the pedagogical affordances of AR-assisted learning, teachers would be able to connect their instruction to many key learning strategies such as higher-order thinking, problem-solving interaction and collaboration which turns their teaching to be more effective and engaging to learners. On the other hand, by taking advantage of the advent of modern sophisticated technologies, students' learning is expected to be transformed from conventional pedagogical strategies into technology-supported pedagogical methods which draw together all major components of a meaningful, successful learning process including learners, knowledge, context, and technology (Dewey 1959). Putting all these together, such pedagogical shift is a real attempt towards employing innovative instructional approaches to attend the distinct learning needs of technology savvy learners labeled as "digital natives".

\section{References}

Alkhattabi, M. (2017). Augmented Reality as E-learning Tool in Primary Schools' Education: Barriers to Teachers' Adoption. International Journal of Emerging Technologies in Learning, 12(2), 91-100.

https://doi.org/10.3991/ijet. v12i02.6158

Azuma, R.T. (1997). A survey of augmented reality. Presence, 6(4), 355-385

Bethany Cohn Sansone. (2015). Evaluating Educators' Perceived Value of Augmented Reality in the Classroom. Dissertation, 119. https://doi.org/305168250

Bitter, G., \& Corral, A. (2014). The Pedagogical Potential of Augmented Reality Apps. International Journal of Engineering Science Invention, 3(10), 13-17.

Bower, M., Howe, C., Bower, M., Howe, C., Mccredie, N., Robinson, A., ... Robinson, A. (2014). Augmented reality in Education - Cases, places, and potentials Augmented, (March 2016).

https://doi.org/10.1080/09523987.2014.889400

Brophy, J. (2010). Motivating Students to Learn Second Edition.

Brown, J. S., Collins, A., \& Duguid. (1989). Situated cognition and the culture of learning. Educational Researcher, 18(1), 32-42.

Bullhound, G. (2018). TECHNOLOGY PREDICTIONS. GP BULLHOUND TECHNOLOGY PREDICTIONS.

Bujak, K. R., Radu, I., Catrambone, R., MacIntyre, B., Zheng, R., \& Golubski, G. (2013). A psychological perspective on augmented reality in the mathematics class- room. Computers \& Education, 68, 536e544. 
Cabero, J., \& Barroso, J. (2016). The educational possibilities of Augmented Reality, 5(1), 44-50. https://doi.org/10.7821/naer.2016.1.140

Champney, Roberto \& Lackey, Stephanie \& Stanney, Kay \& Quinn, Stephanie. (2015). Augmented Reality Training of Military Tasks: Reactions from Subject Matter Experts. Lect Notes Comput Sci. 9179. 251-262. 10.1007/978-3319-21067-4_26.

Cascales, A., Pérez-López, D., \& Contero, M. (2013). Study on parents' acceptance of the augmented reality use for preschool education. Procedia Computer Science, 25(December), 420-427.

https://doi.org/10.1016/j.procs.2013.11.053

Chen, C., \& Wang, C. (2015, December 14-16). The Effects of Learning Style on Mobile Augmented-RealityFacilitated English Vocabulary Learning. Paper presented at Information Science and Security (ICISS). https://dx.doi.org/10.1109/icissec.2015.7371036

Cheng, K. H. (2017). Reading an augmented reality book: An exploration of learners' cognitive load, motivation, and attitudes. Australasian Journal of Educational Technology, 33(4), 53-69. https://doi.org/10.14742/ajet.2820

Coie, P. (2018). Augmented and Virtual Reality Survey Report Industry Insights Into the Future of Ar / Vr, 1-22.

Dede, C. (2005a). "Planning for neomillennial learning styles," EDUCAUSE Quarterly, volume 28, issue 1, pp. 7-12, and at http://www.educause.edu/ir/library/pdf/eqm0511.pdf, accessed 31 October 2007.

Dede, C. (2005b). "Planning for neomillennial learning styles: Implications for investments in technology and faculty," In: D.G. Oblinger and J.L. Oblinger (editors). Educating the net generation, pp. 15.1-15.22, at http://net.educause.edu/ir/library/pdf/pub71010.pdf, accessed 16 March 2009.

Deloitte. (2018). Augmented reality: on the cusp of reality.

Devaney, L. (2010). Augmented reality takes hold in classrooms. Retrieved from http://www.eschoolnews.com/2010/05/11/augmented-reality-takes-hold-in classrooms/

Dewey J. (1959). The child and the curriculum, University of Chicago press.

Diaz, C., Hincapié, M., \& Moreno, G. (2015). How the Type of Content in Educative Augmented Reality Application Affects the Learning Experience. Procedia Computer Science, 75(Vare), 205-212. https://doi.org/10.1016/j.procs.2015.12.239

Diegmann, P., Schmidt-kraepelin, M., Eynden, S. Van Den, \& Basten, D. (2015). Benefits of Augmented Reality in Educational Environments - A Systematic Literature Review. Wi, 3(6-2015), 1542-1556.

Dunleavy, M., Dede, C., \& Mitchell, R. (2009). Affordances and limitations of immersive participatory augmented reality simulations for teaching and learning. Journal of Science Education and Technology, 18, 7-22. doi:10.1007/s10956-008-9119-1

Dunleavy, M., \& Dede, C. (2014). Augmented reality teaching and learning. ... of Research on Educational Communications and ..., 1-34. https://doi.org/10.1007/978-1-4614-3185-5

Edelson, D. C., Gordin, D. N., and Pea, R. D. (1999). Addressing the challenges of inquiry-based learning through technology and curriculum design. Journal ofthe learning sciences, 8(3-4):391-450.

Filer, D. (2010). Everyone's answering: Using technology to increase classroom participation. Nursing Education Perspectives, 31(4), 247-250. Retrieved from http://www.nlnjournal.org/

FitzGerald, E., Ferguson, R., Adams, A., Gaved, M., Mor, Y., and Thomas, R. (2013). Augmented reality and mobile learning: the state of the art. International Journal ofMobile and Blended Learning, 5(4):43-58.

Fotaris, P., Pellas, N., Kazanidis, I., \& Macedonia, E. (2017). A systematic review of Augmented Reality game-based applications in primary education, (October).

Freitas, R. (2008). SMART : a SysteM of Augmented Reality for Teaching 2 nd Grade Students, (April), 4. https://doi.org/10.1145/1531826.1531834

Gopalan, V., Zulkifli, A. N., \& Aida, J. (2016). A Study of Students' Motivation Based on Ease of Use, Engaging, Enjoyment and Fun Using the Augmented Reality Science Textbook. Revista de La Facultad de Ingeniería, 31(2006), 27-35. https://doi.org/10.21311/002.31.5.04

Gopalan, V., Zulkifli, A. N., \& Bakar, J. A. A. (2016). A learning performance study between the conventional approach and augmented reality textbook among secondary school students, 020039 (August), 020039. https://doi.org/10.1063/1.4960879 
Gopalan, V., Zulkifli, A. N., Fadziana, N., Mohamed, F., Alwi, A., Mat, C., ... Saidin, A. Z. (2016). Augmented Reality Books For Science Learning-A Brief Review. International Journal Of Interactive Digital Media, 4(1), 2289-4098. Retrieved from www.ijidm.org

Hsiao H., Chang, C., Lin, C., \& Wang, Y. (2016). Weather observers: a manipulative augmented reality system for weather simulations at home, in the classroom, and at a museum. Interactive Learning Environments, DOI: $10.1080 / 10494820.2013 .834829$

Hung, Y.-H., Chen, C.-H., \& Huang, S.-W. (2017). Applying augmented reality to enhance learning: a study of different teaching materials. Journal of Computer Assisted Learning, 33(3), 252-266.

Jones, C., \& Shao, B. (2011). The Net Generation and Digital Natives Implications for Higher Education. Higher Education Academy, (June), 1-56. Retrieved from

http://www.heacademy.ac.uk/resources/detail/evidencenet/net-generation-and-digital-natives

Kerawalla, L., Luckin, R., Seljeflot, S., \& Woolard, A. (2006). Making it real: Exploring the potential of augmented reality for teaching primary school science. Virtual Reality, 10(3-4), 163-174. https://doi.org/10.1007/s10055006-0036-4

Khadjooi, K., Rostami, K., \& Ishaq, S. (2011). How to use Gagne's model of instructional design in teaching psychomotor skills. Gastroenterology and Hepatology from Bed to Bench, 4(3), 116-9. Retrieved from http://www.ncbi.nlm.nih.gov/pubmed/24834168\%5Cnhttp://www.pubmedcentral.nih.gov/articlerender.fcgi?ar tid=PMC4017416

Laine, T. H. (2018). Mobile Educational Augmented Reality Games : A Systematic Literature Review and Two Case Studies. https://doi.org/10.3390/computers7010019

Liarokapis, F., \& Anderson, E. F. (2010). Using Augmented Reality as a Medium to Assist Teaching in Higher Education. Proc. of the 31st Annual Conference of the European Association for Computer Graphics. Retrieved from http://eprints.bournemouth.ac.uk/20907/1/eg_eduAR10.pdf

Manganello, F. (2010). Constructivist instruction: Success or failure? Educational Technology \& Society, 13(3), 281-284.

Martín-Gutiérrez, J., Mora, C. E., Añorbe-Díaz, B., \& González-Marrero, A. (2017). Virtual technologies trends in education. Eurasia Journal of Mathematics, Science and Technology Education, 13(2), 469-486. https://doi.org/10.12973/eurasia.2017.00626a

Megahed, N. A. (2014). Augmented Reality Based - Learning Assistant for Architectural Education, 1, 35-50.

Monroe, M. (2013). Can Education Change Society? School of Forest Resources and Conservation, UF Mcmonroe@ufl.Edu.

Moralishvili, S., \& Akaki, -. (2014). Augmented Reality in Foreign Language Learning.

Ngussa, B. M., \& Centre, M. (2014). Gagne 's Nine Events of Instruction in Teaching-Learning Transaction : Evaluation of Teachers by High School Students in Musoma- Tanzania. International Journal of Education and Research, 2(7), 189-206.

Oblinger, D., \& Oblinger, J. (2005). Is it age or IT: First steps to understanding the ne generation. In D. Oblinger, \& J. Oblinger, (Eds.), Educating the net generation (1). Retrieved from www.educause.edu/educatingthenetgen/

Pace, F. De, Manuri, F., \& Sanna, A. (2018). Augmented Reality in Industry 4.0, 1-7. https://doi.org/10.21767/2349-3917.100017

Palfrey, J., and Gasser, U. (2008). Born digital: Understanding the first generation of digital natives. New York: Basic Books.

Pellas, N., Fotaris, P., Kazanidis, I., Macedonia, E., \& Wells, D. (2018). Augmenting the learning experience in Primary and Secondary school education : A systematic review of recent trends in augmented reality game-based learning, (May), 0-20. https://doi.org/10.1007/s10055-018-0347-2

Prensky, M. (2001a). Digital Natives, Digital Immigrants. On the Horizon, 9(5), 1-6. https://doi.org/10.1108/10748120110424816

Pretti-Frontczak, K., \& Bricker, D. (2004). An activity-based approach to early intervention (3rd ed.). Baltimore: Brookes.

Prokopenko, A. (2017). Affordances of Augmented Reality for Education : Case study of MoleQL - Mobile Application for Learning Chemistry. 
Rezende, W. J., Albuquerque, E. S., \& Ambrosio, A. P. (2017). Use of Augmented Reality to Support Education Creating a Mobile E-learning Tool and using it with an Inquiry-based Approach. Proceedings of the 9th International Conference on Computer Supported Education, 1(Csedu), 100-107. https://doi.org/10.5220/0006318701000107

Safar, A. H. (2017). The Effectiveness of Using Augmented Reality Apps in Teaching the English Alphabet to Kindergarten Children: A Case Study in the State of Kuwait. EURASIA Journal of Mathematics, Science and Technology Education, 13(1), 417-440. https://doi.org/10.12973/eurasia.2017.00624a

Saltan, F., \& Arslan, O. (2017). The use of augmented reality in formal education: A scoping review. Eurasia Journal of Mathematics, Science and Technology Education, 13(2), 503-520. https://doi.org/10.12973/eurasia.2017.00628a

Sampaio, D., \& Almeida, P. (2016). Pedagogical Strategies for the Integration of Augmented Reality in ICT Teaching and Learning Processes. Procedia Computer Science, 100, 894-899. https://doi.org/10.1016/j.procs.2016.09.240

Sdk, S., Amin, D., \& Govilkar, S. (2015). C OMPARATIVE S TUDY OF A UGMENTED R EALITY, 5(1), 11-26. https://doi.org/10.5121/ijcsa.2015.5102

Shirazi, A., \& Behzadan, A. (2013). Assessing the pedagogical value of augmented reality-based learning in construction engineering 1 , (October), 30-31.

Silva, M. M. O. da, Roberto, R., \& Teichrieb, V. (2015). Evaluation of Augmented Reality Technology in the English Language Field, (Sbie), 577. https://doi.org/10.5753/cbie.sbie.2015.577

Sladek, B. S., \& Grabinger, A. (2016). The first generation of the 21st Century has arrived!, 16. Retrieved from www.xyzuniversity.com

Slijepcevic, N. (2013). The Effect of Augmented Reality Treatment on Learning , Cognitive Load, and Spatial Visualization Abilities.

Sliusar, R. (2017). Augmented reality as a future of the education Case study of MoleQL - educational augmented reality application.

Solak, E., \& Cakir, R. (2015). Exploring the Effect of Materials Designed with Augmented Reality on Language Learners' Vocabulary Learning. Journal of Educators Online, 12(2), 50-72. Retrieved from http://search.proquest.com/docview/1720061545?accountid=14744

Sommerauer, P., \& Müller, O. (2014). Augmented reality in informal learning environments: A field experiment in a mathematics exhibition. Computers \& Education, 79, 59e68. doi: 10.1016/j.compedu.2014.07.013

Tsai, C. (2008). Application of the events of instruction in the Gagné-Briggs ISD Model : A design example in language instruction. Wenzao University of Languages Institutional Reposity, (1). Retrieved from http://ir.lib.wtuc.edu.tw:8080/dspace/handle/987654321/207

Wong, Y. L. (2018). Utilizing the principles of Gagne\&rsquo;s nine events of instruction in the teaching of Goldmann Applanation Tonometry. Advances in Medical Education and Practice, Volume 9, 45-51. https://doi.org/10.2147/AMEP.S145498

Wu, H. K., Lee, S. W. Y., Chang, H. Y., \& Liang, J. C. (2013). Current status, opportunities and challenges of augmented reality in education. Computers and Education, 62, 41-49.

https://doi.org/10.1016/j.compedu.2012.10.024

Yilmaz, R. M. (2016). Educational magic toys developed with augmented reality technology for early childhood education Computers in Human Behavior. Computers in Human Behavior, 54(November 2015), 240-248.

https://doi.org/10.1016/j.chb.2015.07.040 